STUDIA ROSSICA POSNANIENSIA, vol. XLI: 2016, pp. 213-220. ISSN 0081-6884.

Adam Mickiewicz University Press, Poznań

\title{
КОНЦЕПЦИЯ НАЦИОНАЛЬНОГО ХАРАКТЕРА В КОНТЕКСТЕ ИРОНИЧЕСКОГО В РОМАНЕ ИВЛИНА ВО НЕЗАБВЕННАЯ
}

\author{
NATIONAL CHARACTER AND ITS IRONIC REPRESENTATION \\ IN EVELYN WAUGH'S NOVEL THE LOVED ONE
}

\author{
ЕКАТЕРИНА РЯБЧИКОВА
}

\begin{abstract}
The paper is devoted to a study of national character in Evelyn Waugh's work The Loved One. The ironic representation of British and American national characters is analyzed in the paper.

Екатерина Рябчикова, Балтийский Федеральный Университет имени Иммануила Канта, Калининград - Россия, ryabchikova_ekaterina@mail.ru
\end{abstract}

Национальный характер, идентичность и этнические стереотипы в глобализирующемся мире входят в орбиту наиболее актуальных межкультурных и междисциплинарных проблем. Не остается в стороне и литературоведение. Как и всегда, мастера художественного слова интуитивно предвосхищают постановку тех проблем, которые спустя годы будут решать психологи, философы и культурологи. Художественный образ, обращаясь к конкретике человеческого бытия, помогает избежать стереотипного взгляда на проблему национального характера. Этому способствует богатая палитра средств раскрытия национально колоритных образов на разных уровнях организации художественного текста (жанр, нарративная структура, хронотоп, художественная речь). В настоящей статье мы рассмотрим художественно-речевой пласт романа Ивлина Во Незабвенная в его функции выражения авторской иронии.

Проблема национального характера в романе Ивлина Во Незабвенная определяется уже самим подзаголовком „англо-американская трагедия", который в свою очередь интертекстуально соотносится с произведением Теодора Драйзера Американская трагедия. В этом романе Драйзер окончательно развеивает американскую мечту, согласно которой „любой чистильщик сапог может стать миллионером". Подзаголовком „англо-американская трагедия" Во не только подтверждает эту точку зрения, но и подчеркивает, что „упадок и разрушение” характерны не только для американской, но и для английской культуры, то 
есть находится „по ту сторону” стереотипного противопоставления американского „культа прогресса”1 английскому традиционализму. Проблема национального характера получает освещение в рамках художественного мира писателя с разных сторон: автор рассматривает проявления национальных особенностей при межкультурном взаимодействии героев-англичан с американцами, а также при внутрикультурном общении англичан между собой.

В.Г. Крысько приводит следующее определение: „Национальный характер - это исторически сложившаяся совокупность устойчивых психологических черт нации" 2. Однако в настоящее время ведутся дискуссии относительно самого факта существования национального характера. В западной гуманитаристике данная проблема зачастую решается отрицательно. Популярна мысль К. Поппера о том, что „ни одна из теорий, утверждающих, что нация объединена общим происхождением или общим языком, или общей историей, не является приемлемой или применимой на практике"3, а следовательно, и национальный характер - это некий фантомный” , „виртуальный” конструкт.

В отечественной гуманитарной науке в XX веке философ и социолог И. Кон также выразил скептическое отношение к самой постановке проблемы национального характера:

Тайная „голубая” мечта - составить на каждый народ вроде психологического паспорта-характеристики, который давал бы его индивидуальный портрет. Увы, это неосуществимо даже для отдельного индивида ${ }^{4}$.

Однако следует отметить тот факт, что в отечественной гуманитарной науке в целом доминирует позитивное решение проблемы национального характера. Д.С. Лихачев рассуждает о нем следующим образом:

Национальные особенности - достоверный факт. Не существует только каких-то единственных в своем роде особенностей, свойственных только данному народу, только данной нации, только данной стране. Все дело в некоторой их совокупности и в кристаллически неповторимом строении этих национальных и общенациональных черт. Отрицать наличие национального характера, национальной индивидуальности - значит делать мир народов очень скучным и серым 5 .

1 См. об этом: У. Л и п п м а н, Общественное мнение, Москва 2004, с. 118-119.

2 Этнопсихологический словарь, МПСИ. В.Г. Крысько, Москва 1999, с. 190.

${ }^{3}$ К. П о п п е р, Открытое общество и его враги: 6 2-х т., т. 2, Москва 1992, с. 63-64.

4 И.С. К о н, Нужна помощь психологов, „Советская этнография” 1983, № 3, c. $75-76$

5 Д.С. Л и х а ч е в, О национальном характере русских, „Вопросы философии" 1990, № 4, c. 3. 
Мы придерживаемся мнения, что национальный характер не является чисто номинальным образованием. Более того, мы полагаем, что национальная классическая художественная литература является наиболее значимым источником информации о нем. В романе Во Незабвенная проблема национального характера решается автором в контексте эстетических категорий иронического и трагического.

В литературной энциклопедии ирония определяется как „иносказание, задача которого - высмеять определенное явление или человека за счет употребления слов в противоположном значении, осуждение под видом похвалы"6. Разновидности иронии обусловлены функционально. Так, ирония, имеющая экзистенциальный статус, обозначается как трагическая. Противоречие, лежащее в ее основе, заключается в том, что „именно свободное действие человека реализует губящую его неотвратимую необходимость, которая настигает человека именно там, где он пытался преодолеть ее или уйти от нее"7.

Уже в самом названии романа Во заключена трагическая ирония. Оригинальное название романа The Loved One дословно означает „Любимый / Любимая". Рассматривая понятие любви в контексте американской и британской культур, мы не находим выражения сильного сердечного чувства. Как утверждает В.П. Шестаков,

отношение американцев к любви прагматично и рационально. [...] Искусство любви мало чем отличается от искусства приготовления пищи: все зависит от наличия ингредиентов и правильной пропорции в их приготовлении ${ }^{8}$

По мнению Д. Рейфилда, „англичанин и англичанка ищут в любви не горячку, не пожар, а удобную душевную батарею" 9 . Любовь в современном прагматическом сознании англичан и американцев рассматривается как удобное приобретение, она лишена романтического ореола. Во наделяет главную героиню своего романа „говорящим" экзотическим именем - Эме Танатогенос (Aimée Thanatogenos), что означает „Любимая, смертью рожденная". Именно к ней он относит название

6 Литература и язык. Современная иллюстрированная энииклопедия, под ред. А.П. Горкина, Росмэн, Москва 2006, с. 617.

7 Философский энциклопедический словарь, гл. редакция: Л.Ф. Ильичев, П.Н. Федосеев, С.М. Ковалев, В.Г. Панов, Советская энциклопедия, Москва 1983, с. 691.

8 Ш е с т а к о в В.П. Американская культура: $b$ поисках национальной идентичности (часть II), „Культурологический журнал” 2013, № 1, [в:] электронный ресурс: http://cr-journal.ru/rus/journals/183.html\&j_id=13 (20.11.2015).

9 Д. Р е й ф и л д, Заметки об Англии, „Иностранная литература” 1994, № 6, [в:] электронный ресурс: http://trans.corp7.uniyar.ac.ru/for-translators/supportingliterature.html (20.11.2015). 
The Loved One - любимая, которую на самом деле не любили, но именно эту девушку главные герои никогда не смогут забыть. Следует отметить также мастерский перевод романа на русский язык: Борис Носик не только конкретизировал название с точки зрения гендера, но и подобрал слово, наиболее точно передающее оттенок английского „loved” для русской культуры - „незабвенная".

В романе, действие которого происходит в США, английский национальный характер реализуется прежде всего в образах англичан-эмигрантов, представителей среднего класса. Именно с образами англичан связано ироническое начало его романа: Во изображает их полную уверенность в собственной правоте и превосходстве, а также то огромное количество правил и представлений о том, что „прилично”, а что нет, регламентирующих их повседневную жизнь. Образы персонажей-носителей английского национального характера пронизаны автостереотипностью, в которой также сквозит ирония. Колония англичан в США является воплощением таких типично английских качеств, как консерватизм, снобизм, приверженность традициям:

По-настоящему в крикет здесь играли лишь несколько молодых членов клуба: что касается подавляющего большинства его членов, то крикет занимал в сфере их интересов столь же малое место, как, скажем, торговля рыбой с лотка или сапожный промысел в оборотах лондонских оптовиков. Для них клуб был просто символом их принадлежности к английскому клану [...]. Здесь они могли вволю позлословить, не боясь, что их услышат чужеземные хозяева и покровители ${ }^{10}$.

Как справедливо отметил Г. Анджапаридзе, образ Эмброуза Эберкромби, „столпа" британской колонии в Америке, на протяжении всего романа выписывается автором с нескрываемой издевкой. Все, что осталось от Англии у сэра Эмброуза, - это „итонский галстук и совершенно абсурдный снобизм, выливающийся в глупейшие разговоры об «особом» месте англичан"11. В рассуждения Эмброуза Эберкромби о великом предназначении англичан автор намеренно вкладывает затертые клише keep the flag flying, show the flag (не уронить марку, держать марку), причем персонаж каждый раз в разговоре об английской колонии употребляет одни и те же речевые клише. Таким образом И. Во косвенно показывает своему читателю, что сэр Эмброуз - ограниченный сноб, который не умеет выйти за пределы обмена этими клише. Они служат для него средством упрощения коммуникативной ситуации - для него намного легче отстаивать свое мнение избранными

10 И. В о, Избранное, перев. с англ., Лумина, Кишинев 1978, с. 487.

11 Г.А. А н д ж а п а р и д з е, Предисловие, [в:] И. В о, Избранные произведения, 3-е изд., Москва 1982, с. 16. 
раз и навсегда языковыми средствами, а это в свою очередь косвенно подчеркивает еще и скудость его интеллекта.

Главный герой романа, поэт Деннис Барлоу, является динамичным персонажем, он способен изменить себя и пытается понять чужую культуру, быт, традиции. Уже в начале повествования он потерял лицо перед своими соотечественниками - устроился работать похоронщиком на „собачье кладбище” (pet's cemetery). Хотя в поведении Денниса автором нарочно и заостряются некоторые специфически неприятные черты, служащие гротескному обыгрыванию ситуации, он все же выступает рупором писателя, носителем свежего взгляда в незнакомом месте, взгляда нормального человека, попадающего в извращенный мир. Именно с помощью Денниса Во обнажает истинную сущность происходящих событий, показывает процесс деградации американского образа жизни. Лишь в нескольких случаях автор позволяет себе дать оценку Америке от первого лица.

Так, например, Во мастерски использует перифраз, заменяя название страны (США) описанием ее определяющих черт и признаков, создающих полную и яркую картину. Чтобы показать безвкусицу, претенциозность американского образа жизни, вторичность многих его эстетических и этических ценностей, автор использует „злую” иронию, сарказм, что объясняется выбором мастерски подобранного художественного слова - это „рай” (Eden), „страна безродных и заблудших" (land of waifs and strays). Выбор именно этих слов для описания США, во-первых, отсылает нас к далеко не образцовому прошлому этой страны (ведь всем известно, что сначала туда ссылали неугодных в Англии преступников, бродяг и бандитов), а во-вторых, к притче о блудном сыне, которая в данном случае является иронически освещенной евангельской коннотацией. С помощью эпитетов „безличное и равнодушное дружелюбие" (impersonal insensitive friendliness), "бесцеремонность обращения и откровенность высказываний" (unceremonious manners and frank speech) автор описывает свойственную американцам логику коммуникации - с одной стороны, конвенционально-безличную, с другой стороны, эмоционально-экспрессивную, но в обоих случаях чуждую эмпатии - сопереживанию ближнему, то есть по сути своей чуждую христианским ценностям, что дополняет образ Америки еще одной отрицательной чертой.

Главная героиня романа, Эме Танатогенос, одновременно и порождение американского образа жизни, и его жертва. Эме является воплощением женственности, уже исчезающей в современном прагматическом мире. В то же время, несмотря на постоянно подчеркиваемое автором отличие героини от других „однотипных” американок, по верному утверждению С.Н. Филюшкиной, 
в поведении Эме, ее психологии, представлениях о жизни, усиленно подчеркивается тот примитивизм, та стандартность мышления, которые призваны представить героиню „продуктом” узкого пуританского воспитания, прагматического подхода к жизни, влияния массовой культуры, всепроникающей рекламы ${ }^{12}$.

Эти особенности американской культуры представлены в романе с резко отрицательной оценкой. Прежде всего, автор высмеивает американский культ „самого-самого”, погоню за идеалом, рекламу как одно из проявлений американского образа жизни и стремление на всем делать деньги. Все это органически переплелось в образе „Шелестящего дола" (Whispering Glades) - элитной похоронной конторы. В романе действие главного героя, „поэта и собачьего похоронщика” (poet and pets' mortician) Денниса, проезжающего в первый раз ворота кладбища „Шелестящий дол”, благодаря сравнению приравнивается по значимости к таким „священным” актам, как первое посещение Ватикана священником-миссионером или первое восхождение верховного вождя на Эйфелеву башню. Более того, выражение „поэт и собачий похоронщик", помимо явной антитетичности сфер высокого и низкого, содержит еще дополнительный паронимический эффект, основанный на созвучиях слов „поэт” (poet) и „собачий” (pet's) по-английски. Благодаря этим стилистическим приемам явственно сквозит ирония автора, осуждающая иррациональный облик современной цивилизации. Вместе с Деннисом читатель переступает порог „Шелестящего дола”, этого мира „наоборот”, мира, в котором нет ничего естественно человеческого, поскольку здесь надругательству подвергаются и смерть, и жизнь.

Однако „миром наоборот” в романе оказывается не только похоронная контора. На наш взгляд, Новый Свет - это карнавализированная, перевернутая Англия, в которой консерватизм, чопорность, ограниченность и снобизм оборачиваются цинизмом и вседозволенностью, то есть Новый Свет - это не что иное, как „кривое зеркало” Старого.

Занимаясь саморекламой, „Шелестящий дол” не скупится на обещания для своих клиентов, развертывая перед ними тот образ, который они желают - если они выберут именно это похоронное бюро, то они не просто будут считаться элитой общества и лишний раз подчеркнут свой статус, более того, имена их „будут жить вечно” (their name liveth for evermore), что позволит им войти в историю, а будущим поколениям знать таких „великих” людей. „Шелестящий дол” идет

12 С.Н. Ф и л ю ш к и н а, Зарубежная литература ХХ века: раздумья о человеке. Учебно-методическое пособие, Воронежский государственный университет, Воронеж 2002, c. 107. 
в ногу со временем, следя за политической ситуацией в мире и, не стесняясь, дает гарантии своим клиентам, что их бесценные могилы останутся „нетронутыми даже при ядерном взрыве” (It is certified proof against nuclear fission). Здесь гипербола в рекламном тексте похоронной конторы достигает своего максимума, развеивая у большинства клиентов „Шелестящего дола” последние капли сомнения, а у читателя вызывая лишь горькую улыбку.

Согласно американскому образу жизни быть некрасивой просто неприлично, „любая женщина должна стремиться стать идеальной, как модели на обложках журналов"13. Масса сил и средств уходит на то, чтобы придерживаться общепринятого стандарта красоты. Однако погоня за „идеалом" в этой стране убивает все признаки уникальности, в результате чего не только во внешнем облике, но и в поведении людей прослеживается пугающее сходство, которое мастерски определил Во: „стандартный продукт” (the standard product). Образ такого „стандартного продукта” дополняется принятым в США конвенциональным общением, исходящим исключительно из безличных норм и стандартов. Это особенно показательно в общении Денниса со служащей „Шелестящего дола”, которая перемежает в своей речи фразы, характерные для нее как для служащей своего учреждения, и собственные комментарии.

Еще одна черта национального характера американщев - стремление к успеху и желание делать деньги - высмеивается автором в небольшом эпизоде, когда преподобный Эррол Бартоломью, отпевающий домашних животных, отмечает, что некоторые „новички” (имеются в виду пасторы) берутся даже за психиатрию и столоверчение, однако даже при этом, а может быть и благодаря этому, служители культа в Америке пользуются глубочайшим уважением среди американцев.

Показателем американского характера можно считать также американскую улыбку. Известно, что американец жизнерадостен или, по крайней мере, улыбчив, особенно на работе. Начальник должен показать подчиненным, а подчиненные - клиентам, покупателям, что „у меня все О’кей!”. Как справедливо отмечает С. Тер-Минасова, „в западной культуре улыбка - это обязательный компонент обслуживания, формальный знак культуры, не имеющий ничего общего с искренним расположением к тому, кому ты улыбаешься"14. В Незабъенной сквозь ироническую призму Во мы видим Улыбку лучезарного детства

13 П.Л. С е м е ш к и н а, Медиабезопасность на рынке СМИ США: американские глянцевые журналы для женщин - тренд-сеттеры или распространители гендерных стереотипов?, „Вестник Челябинского государственного университета” 2013, № 22, с. 149.

${ }_{14}$ С. Т е р - М и н а с о в а, Язык и межкультурная коммуникация, Слово, Москва 2000, c. 190. 
даже на улицах умерших, то есть автор использует здесь прием гиперболы, доводит стандартизированный образ американца до абсурда.

Таким мы видим типичного представителя американского национального характера в произведении Во Незабвенная - улыбчивого и жизнерадостного, стремящегося на всем делать деньги, не переходящего черту поверхностного знакомства, с сильной эгоцентрической составляющей. В образе англичанина проявляется приверженность традициям, снобизм и высокомерие, скудость эмоций, практичный склад ума и здравомыслие. В произведении Во Незабвенная в контексте иронического автором показывается столкновение Англии с ее исторической тягой к прошлому и Америки с ее культом прогресса - англо-американская трагедия. Писатель создает обобщенный образ чудовищного и трагического по своей сути мира. Художественно-речевой пласт романа в его функции выражения авторской иронии отражает „упадок и разрушение" современной цивилизации, которую Во высмеивает и отрицает.

\section{Библиография}

А н д ж а п а р и д з е Г.А., Предисловие. Текст, [в:] И. В о, Избранные произведения, 3-е изд., Москва 1982.

В о И., Избранное, перев. с англ., Лумина, Кишинев 1978.

К о н И.С., Нужна помощь психологов, „Советская этнография” 1983, № 3, с. 75-76.

Л и п п м а н У., Общественное мнение, Москва 2004.

Литература и язык. Современная илюстрированная энииклопедия, под ред. А.П. Горкина, Росмэн, Москва 2006.

Л и х а ч е в Д.С., О национальном характере русских, „Вопросы философии” 1990, № 4, c. 3.

П о п п е р К., Открытое общество и его враги: В 2-х т., т. 2, Москва 1992.

Р е й ф и л д Д., Заметки об Англии, „Иностранная литература” 1994, № 6, [в:] электронный ресурс: http://trans.corp7.uniyar.ac.ru/for-translators/supportingliterature.html (20.11.2015).

С е м е ш к и н а П.Л., Медиабезопасность на рынке СМИ США: американские гляниевые журналы для женщин - тренд-сеттеры или распространители гендерных стереотиnob?, „Вестник Челябинского государственного университета” 2013, № 22, с. 149.

Т е р - М и н а с о в а С., Язык и межкультурная коммуникация, Слово, Москва 2000. Философский энииклопедическии словарь, гл. редакция: Л.Ф. Ильичев, П.Н. Федосеев, С.М. Ковалев, В.Г. Панов, Советская энциклопедия, Москва 1983.

$\Phi$ и л ю ш к и н а С.Н., Зарубежная литература ХХ века: раздумъя о человеке. Учебно-методическое пособие, Воронежский государственный университет, Воронеж 2002.

Ш е с т а к о в В.П., Американская культура: $\mathbf{b}$ поисках национальной идентичности (часть II), „Культурологический журнал” 2013, № 1, [в:] электронный ресурс: http://cr-journal.ru/rus/journals/183.html\&j_id=13 (20.11.2015).

Этнопсихологический словарь, МПСИ. В.Г. Крысько, Москва 1999. 